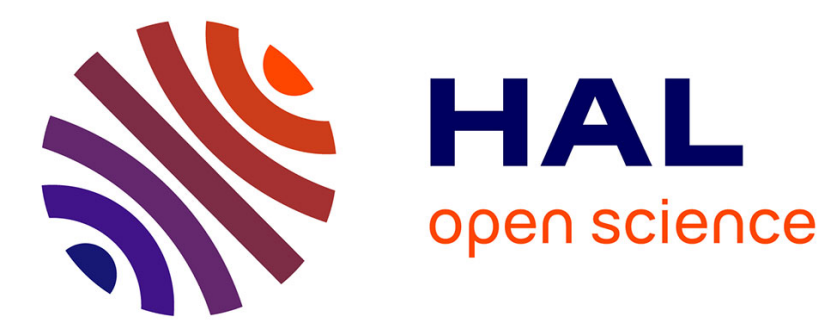

\title{
Self-potential tomography applied to the determination of cavities
}

\author{
Abderrahim Jardani, A. Revil, Jean-Paul Dupont
}

\section{To cite this version:}

Abderrahim Jardani, A. Revil, Jean-Paul Dupont. Self-potential tomography applied to the determination of cavities. Geophysical Research Letters, 2006, 33 (13), pp.113401. 10.1029/2006gl026028 . hal-00484447

\section{HAL Id: hal-00484447 \\ https://hal.science/hal-00484447}

Submitted on 31 May 2021

HAL is a multi-disciplinary open access archive for the deposit and dissemination of scientific research documents, whether they are published or not. The documents may come from teaching and research institutions in France or abroad, or from public or private research centers.
L'archive ouverte pluridisciplinaire HAL, est destinée au dépôt et à la diffusion de documents scientifiques de niveau recherche, publiés ou non, émanant des établissements d'enseignement et de recherche français ou étrangers, des laboratoires publics ou privés. 


\title{
Self-potential tomography applied to the determination of cavities
}

\author{
A. Jardani, ${ }^{1,2}$ A. Revil, ${ }^{3}$ and J. P. Dupont ${ }^{1}$ \\ Received 19 March 2005; revised 26 April 2006; accepted 2 May 2006; published 1 July 2006.
}

[1] A 3D tomography algorithm of self-potential (SP) signals is applied for the first time to the localization of subsurface cavities. A specific application is made to a marl-pit in Normandy (North-West of France). A SP map with a total of $221(5 \mathrm{~m}$-spaced) measurements shows a negative anomaly with an amplitude of $-8 \mathrm{mV}$ associated with the position of the marl pit. To explain these data, we solved the boundary-value problem for the coupled hydroelectric problem associated with the presence of the cavity using a finite-element code. The numerical simulations point out the role of open conduits in electrical charge accumulation near the roof of the cavity and the resistivity contrast between the cavity and the surrounding formation. We applied successfully a SP tomography algorithm showing that the roof of the cavity was associated with a monopole charge accumulation due to the entrance of the ground water flow in a network of open cracks. Citation: Jardani, A., A. Revil, and J. P. Dupont (2006), Self-potential tomography applied to the determination of cavities, Geophys. Res. Lett., 33, L13401, doi:10.1029/ 2006GL026028.

\section{Introduction}

[2] Locating cavities in the ground is an important step in drawing geohazard maps especially in populated areas. In High-Normandy (North-West of France), anthropic cavities have been dug in the chalk since the XVth century until the 1950's to extract chalk blocks used in agriculture to improve the agricultural productivity of acidic soils. Nowadays, these cavities have been abandoned and their shafts plugged. H. Robin (unpublished results, 2003) estimated that more than 100.000 marl-pits could exist in this region. Most of the time, the position of these marlpits is unknown. One can therefore easily imagine the cost induced by their collapse and the need for efficient and cost-effective methods to locate them not only in this region but also in other regions of the world where similar problems exist.

[3] Various geophysical methods have been used to detect caves. Microgravimetry, seismic, and electrical resistivity surveys are expensive while georadar does not perform well if the sediment cover is electrically conductive (e.g., in presence of clay-bearing sediments) like in the case reported below. In this letter, SP tomography is shown to be an efficient method to locate cavities in the

\footnotetext{
${ }^{1}$ Laboratoire de Géologie, Faculté des Sciences, Université de Rouen, Mont Saint Aignan, France.

${ }^{2}$ Also at Bureau d'Etudes ALISE, Saint Jacques-sur-Darnétal, France. ${ }^{3}$ CNRS-CEREGE, Université Aix-Marseille III, Aix-en-Provence, France.
}

Copyright 2006 by the American Geophysical Union. 0094-8276/06/2006GL026028 ground. SP signals correspond to the passive measurement at the ground surface of the electrical potential distribution resulting from polarization processes at play in the ground. The flow of groundwater is responsible for a polarization mechanism known as the streaming potential [Sill, 1983]. Previous works [Lange and Barner, 1995] have shown that water-saturated caves are responsible for positive SP signals at the ground surface while air-filled caves are responsible for negative SP anomalies. Some anomalies show sometimes an $\mathrm{M}$ - or $\mathrm{W}$-shape signal centered on the position of the cave in either case. While Quarto and Schiavone [1996] and Lange [1999, 2000] suggested that these SP anomalies are due to the streaming potential resulting from the percolation of the ground water, Green [2000] suggested they result of steady-state telluric currents and the contrast of electrical resistivity between the cave and the surrounding medium. In this paper, we show how both the percolation of water and the distribution of the electrical resistivity are responsible for the SP anomalies observed at the ground surface of the Earth.

\section{Numerical Simulations}

[4] We simulate below the SP response associated with the presence of a cavity in the ground. Self-potential signals are obtained by solving the Poisson equation $\nabla$. $(\sigma \nabla \varphi)=-\nabla(L \nabla h)$ where $h$ is the total hydraulic head, $L$ (in $\mathrm{A} \mathrm{m}^{-2}$ ) characterizes the electrical current density produced in response to the unit hydraulic gradient, $\sigma$ is the conductivity of the rock, and $\varphi$ the electrical potential (in V).

[5] The presence of a cavity in the ground is responsible for stress concentrations and the formation of a network of cracks [Lange, 2000]. In turn this network of cracks influences the percolation of the ground water. The geometry of our model is shown Figure 1. The geology is similar to the field case reported in section 4 in the karstic chalk of Normandy. The first layer corresponds to a loess cover (from the ground surface to a depth of $2.5 \mathrm{~m}$ ), the second layer to the clay-with-flint formation (between $2.5 \mathrm{~m}$ and $7 \mathrm{~m}$ ), and the third layer (in which is located the cavity) to the chalk formation. The cavity is surrounded by vertical conduits. The material properties of each layer (plus the cave) are reported in Table 1. A flux of efficient meteoric water is imposed at the ground surface. Following Sill [1983], we first solved the steady-state equation for the hydraulic head $h(x, z)$ with the appropriate boundary conditions (given below) and the distribution of the hydraulic conductivity $K(x, z)$. Then, the right-hand side of the Poisson equation for the electrical potential is computed with a given distribution of the current coupling coefficient $L(x, z)$. Finally, the Poisson equation is solved for the electrical potential $\varphi(x, z)$ with a given distribution of the 


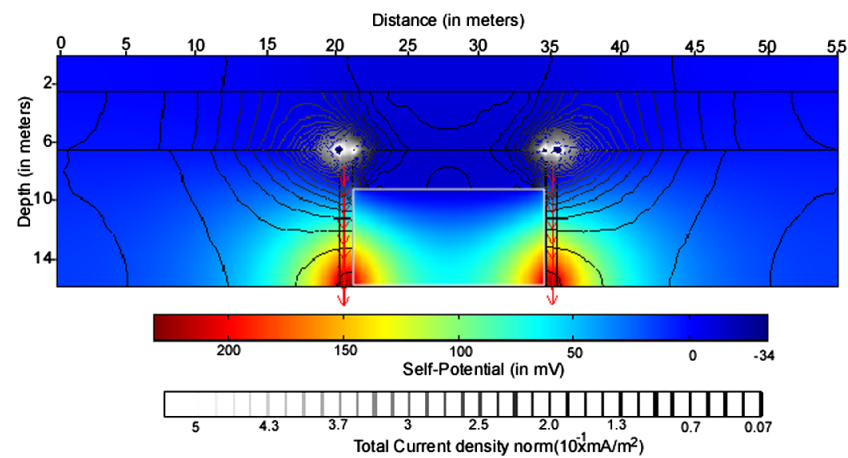

Figure 1. Distribution of the SP determined numerically by the finite element method (FEMLAB). The cave is surrounded by vertical conduits corresponding to a network of open cracks.

electrical conductivity $\sigma(x, z)$. We use the finite-element code FEMLAB to solve this coupled hydro-electric boundary-value problem.

[6] The distribution of the electrical conductivity and the values of the current coupling coefficient and hydraulic conductivity for each of the three lithological units (loess, clay, chalk and cavity) are reported in Table 1 . The values of these parameters were determined by electrical resistivity tomography and core measurements. In addition, the hydraulic conductivity of the conduits is taken equal to $10^{-3} \mathrm{~m} / \mathrm{s}$, a high value by comparison with the hydraulic conductivity of the background in order to impact on the distribution of groundwater flow. The side-boundaries located far from the conduits as seen from the cavity are assumed to be impermeable to force the flow to be vertical. In steady state conditions, the flux at the bottom boundary is equal to the flux of water at the ground surface. For the electrical potential, we assume that the normal component of the current density vanishes at all the boundaries (insulating boundary condition).

[7] We considered three synthetic cases. The first model (case $\mathrm{C} 1$ ) corresponds to a cavity filled with air (very high electrical resistivity). In the second case (case $\mathrm{C} 2$ ), there is no cavity (its resistivity is that of chalk) but we keep the conduits. In the third case (case C3), the cavity is filled with clay or water and is therefore very conductive. The comparison between case 2 and cases 1 and 3 shows the influence of the resistivity distribution upon the resulting self-potential signals.

[8] Lange [1999, 2000] showed that cavities in the ground are characterized by $\mathrm{M}$ - or $\mathrm{W}$-shapes and can take positive or negative values with respect to a reference electrode placed far away. Our numerical simulations

Table 1. Material Properties Used in the Numerical Simulations

\begin{tabular}{llll}
\hline \multicolumn{1}{c}{ Material } & $K, \mathrm{~m} \mathrm{~s}^{-1}$ & $\rho, \Omega \mathrm{m}$ & $L, \mathrm{~A} \mathrm{~m}^{-2}$ \\
\hline Loess & $10^{-6}$ & 70 & $9 \times 10^{-9}$ \\
Clay-with-flint & $10^{-8}$ & 10 & $9 \times 10^{-9}$ \\
Chalk & $10^{-10}$ & 100 & $9 \times 10^{-9}$ \\
Conduits & $10^{-3}$ & 60 & $9 \times 10^{-9}$ \\
Cave, C1 & $10^{-13}$ & 10000 & 0 \\
Cave, C2 & $10^{-10}$ & 100 & $9 \times 10^{-9}$ \\
Cave, C3 & $10^{-12}$ & 10 & $10^{-9}$ \\
\hline
\end{tabular}

(Figure 2) show that the flow of the ground water polarizes the ground. The shapes of the SP signals associated with the three synthetic cases discussed above are shown in Figure 2. When the cavity is air-filled, the SP anomaly is negative while it is positive when the cavity is filled by a conductive material (clay or water). These results point out the role of the distribution of the electrical resistivity of the ground on the shape of the observed SP anomalies. The roof of the cavity is characterized by negative charge accumulations that correspond to the entrance of the ground water in the conduits and percolating in the vicinity of the roof of the cavity. An algorithm designed to detect negative charge accumulations is therefore discussed in section 3 to locate the roof of a cavity from SP signals.

\section{SP Tomography (SPT)}

[9] We note P(r) a SP measurement station located at the ground surface (or possibly in a borehole). The electrical potential measured at this station is $\varphi(\mathbf{r})$. The occurrence of $\mathrm{SP}$ signals in the ground is governed by:

$$
\varphi(\mathbf{r})=\frac{1}{2 \pi} \int_{\Omega} \frac{1}{\sigma\left(\mathbf{r}^{\prime}\right)} \frac{\nabla \cdot \mathbf{j}_{S}\left(\mathbf{r}^{\prime}\right)}{\left|\mathbf{r}-\mathbf{r}^{\prime}\right|} d V+\frac{1}{2 \pi} \int_{\Omega} \frac{\nabla \rho\left(\mathbf{r}^{\prime}\right)}{\rho\left(\mathbf{r}^{\prime}\right)} \frac{\mathbf{E}\left(\mathbf{r}^{\prime}\right)}{\left|\mathbf{r}-\mathbf{r}^{\prime}\right|} d V,
$$

where $\left|\mathbf{r}-\mathbf{r}^{\prime}\right|$ is the distance between $\mathrm{P}$ and the volume element of the ground and $\mathbf{j}_{S}\left(\mathbf{r}^{\prime}\right)=-L \nabla h$ is the source current density in the ground, $d V$ is the source element, and $\Omega$ the volume of integration. The first term of equation (1) is the primary source corresponding to the occurrence of a current density inside the system while the second term corresponds to secondary sources associated with heterogeneities in the distribution of the electrical resistivity $\rho=$ $1 / \sigma$. In the case of a cavity, there is a divergence of the source current density and there is also is a strong contrast in the resistivity distribution between the cavity and the surrounding medium.

[10] Iuliano et al. [2002] proposed a 3-D source element occurrence probability (SEOP). This algorithm is based on

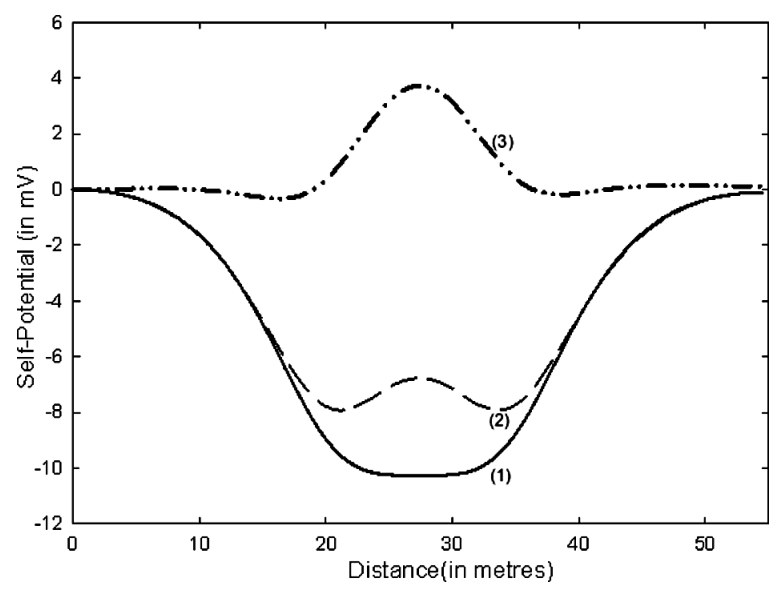

Figure 2. SP curves for different models: the bottom curve indicates the cave is filled with air, the middle curve indicates no cave, and the upper curve indicates the cave is filled with a conductive material. 


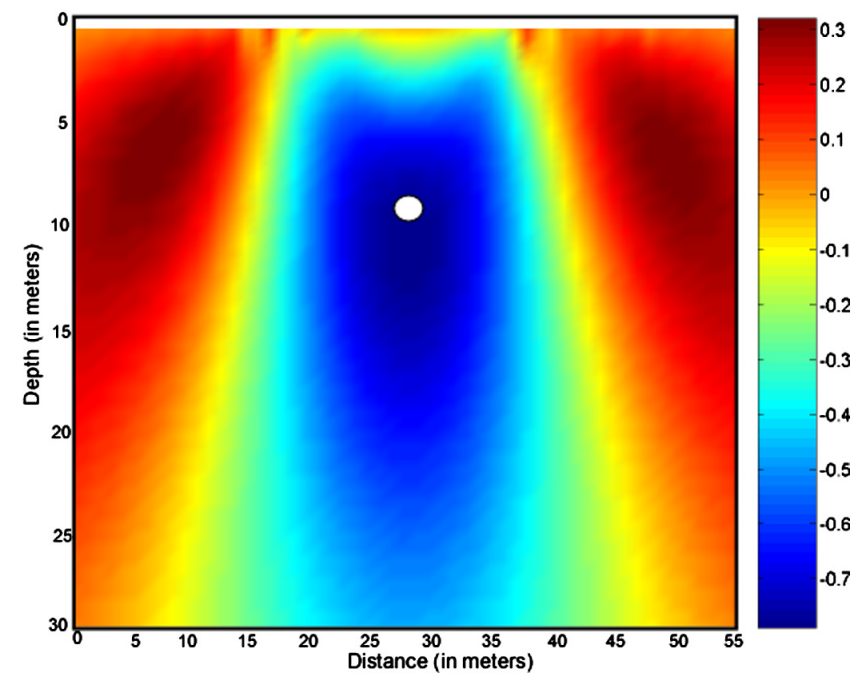

Figure 3. SP tomography (SEOP) applied to the synthetic SP signals in the case of a cave filled with air. The open circle corresponds to the maximum of the SEOP distribution and coincides with the roof of the cavity (see Figure 1).

an intercorrelation between the measured SP signals and that resulting from an elementary monopole or dipole [e.g., Revil et al., 2001] placed at the scanned position. If we assume that the source is the sum of monopoles, the result is a charge occurrence probability density that can be contoured to provide a tomographic image of the areas where charges accumulate. Note that this algorithm does not distinguish between SP sources associated with primary signals (the existence of a source of current in the ground) or secondary sources associated with the existence of resistivity contrasts. In the field case reported below, the cavity is filled with air and therefore very resistive. This implies a strong contrast a resistivity between with cavity and the host rock (chalk). The application of the SP tomography algorithm to the synthetic cases reported above indicates that the maximum of the SEOP is associated with the roof of the cavity (Figure 3).

\section{Field Results}

[11] The test site we used to test the usefulness of the SPT method is located in Normandy, in the North-West of France. A high-resolution SP map (Figure 4) was realized in the Spring of 2005 using non-polarizing $\mathrm{Cu} / \mathrm{CuSO}_{4}$ electrodes and a high internal impedance $(100 \mathrm{M} \Omega$ ) Metrix MX20 voltmeter (sensitivity of $0.1 \mathrm{mV}$ ). The SP map of Figure 4 shows a negative SP anomaly centered around the shaft of the cavity (note the position of the cavity was unknown when the field survey was performed and the shaft was plugged and therefore not visible from the ground surface). The density of the measurements has to be high enough to avoid aliasing of the data. The repeability of the measurements is $1 \mathrm{mV}$ and the determination of the standard deviation of the measurement is equal to $0.8 \mathrm{mV}$ because of the excellent contact between the electrodes and the ground.

[12] Application of the SEOP algorithm is shown on Figure 5. The algorithm provides a clear SP source localization at a depth of $9 \mathrm{~m}$ below the ground surface. Once the shaft was localized and the map of the cavity established, we found that $9 \mathrm{~m}$ was effectively the depth of the roof of the air-filled cavity (see Figure 6). To our knowledge, this is the first time that SPT is applied to the localization of a cavity in the ground.

\section{Conclusions}

[13] This study demonstrates that SPT can successfully locate the position of the roof of an air-filled cavity in the ground. In this case, a negative SP anomaly is observed at the ground surface while a cavity filled with a conductive material generates a positive SP anomaly. This is due to the distribution of the electrical resistivity that influences the distribution of the measured self-potential signals. The

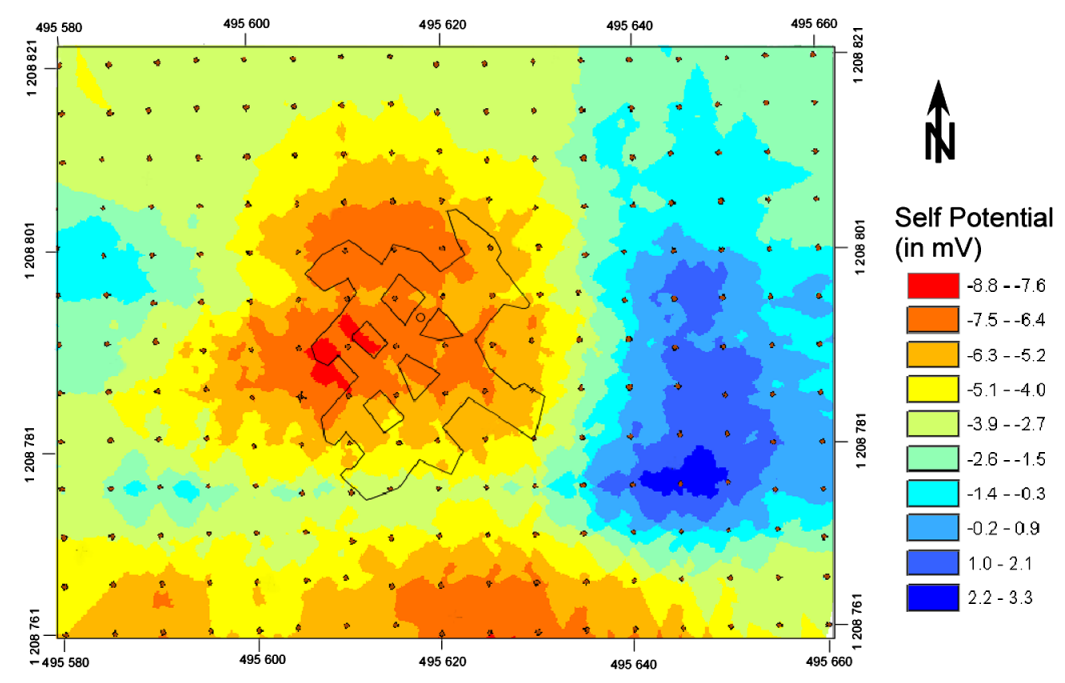

Figure 4. SP map of the investigated area. The spacing between the measurements is $5 \mathrm{~m}$ and the $\mathrm{x}$ and $\mathrm{y}$ coordinates are Cartesian coordinates in meters. The mine shaft corresponds to the small open circle $(x=618 \mathrm{~m}, y=$ $795 \mathrm{~m}$ ) located near the center of the negative SP anomaly. The lines indicate the shape of the cavity including the presence of 5 pillars. 


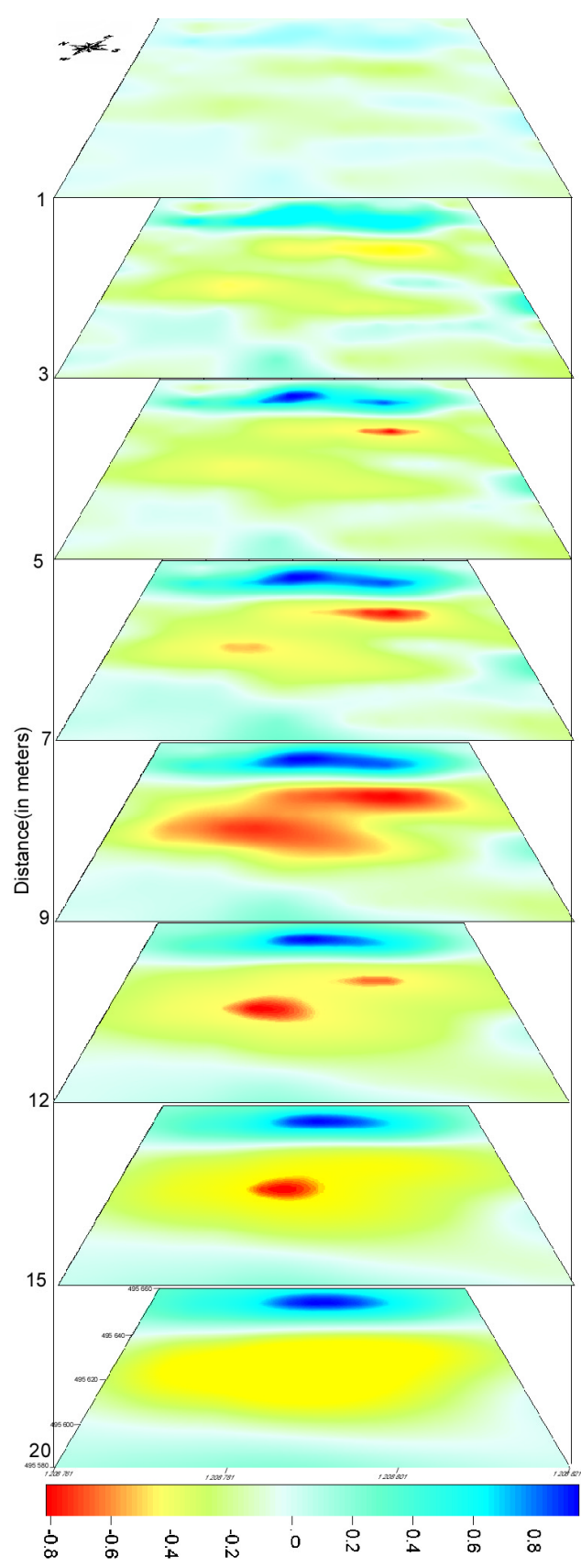

Figure 5. 3D-SP tomography (the SEOP density is comprised between $(-1)$ for negative charge accumulations to $(+1)$ for positive charge accumulations). The negative charge accumulation (in red) indicates the correct position of the roof of the cavity, $9 \mathrm{~m}$ below the ground surface (see Figure 6).

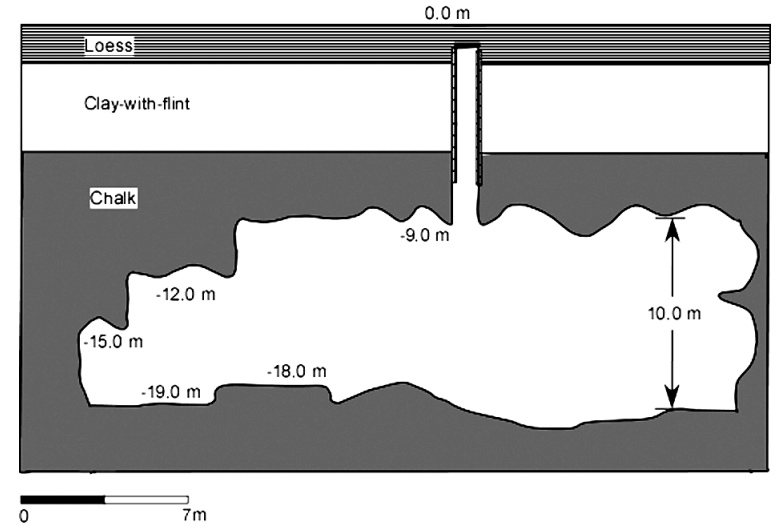

Figure 6. Real shape of the cavity.

advantages of the SP method are (a) its low cost and (b) the fact that a high density of measurements can be performed during a day. It follows that this method is very suitable to draw geohazard map in areas where cavities are suspected to exist. Since the present study, two other cavities have been located in the same region using the SPT methodology.

[14] Acknowledgments. We thank the University of Rouen and the CNRS for their supports. C. Gioa, M. Simon, and T. Leboulanger are thanked for their help in the field. We thank the two referees (Bernd Kulessa and Adrian Cerepi) and the Editor for their constructive comments.

\section{References}

Green, D. J. (2000), Discussion: "Geophysical studies at Kartchner Cavers State Park, Arizona", J. Cave Karst Stud., 62(1), 27.

Iuliano, T., P. Mauriello, and D. Patella (2002), Looking inside Mount Vesuvius by potential fields integrated probability tomographies, $J$. Volcanol. Geotherm. Res., 113, 363-378.

Lange, A. L. (1999), Geophysical studies at Kartchner cavers State Park, Arizona, J. Cave Karst Stud., 61(2), 68-72.

Lange, A. L. (2000), Reply: Geophysical studies at Kartchner cavers State Park, Arizona, J. Cave Karst Stud., 62(1), 28-29.

Lange, A. L., and W. L. Barner (1995), Application of the natural electric field for detecting karst conduits on Guam, in Karst GeoHazards, edited by B. F. Beck, pp. 425-441, A. A. Balkema, Brookfield, Vt.

Quarto, R., and D. Schiavone (1996), Detection of cavities by the SP method, First Break, 48(1), 76-86.

Revil, A., L. Ehouarne, and E. Thyreault (2001), Tomography of selfpotential anomalies of electrochemical nature, Geophys. Res. Lett., 28(23), 4363-4366, doi:10.1029/2001GL013631.

Sill, W. R. (1983), SP modelling from primary flows, Geophysics, 48(1), $76-86$.

J. P. Dupont and A. Jardani, Laboratoire de Géologie, Faculté des Sciences, Université de Rouen, 10 boulevard De Broglie, F-76130 Mont Saint Aignan, France.

A. Revil, CNRS-CEREGE, Université Aix-Marseille III, Europôle de l'Arbois, BP 80, Cedex 20, F-13545, Aix-en-Provence, France. (revil@ cerege.fr) 